\title{
B7-H3 promotes cell migration and invasion through the Jak2/Stat3/MMP9 signaling pathway in colorectal cancer
}

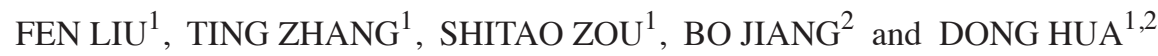 \\ ${ }^{1}$ Institute of Cancer, Affiliated Hospital of Jiangnan University, Wuxi, Jiangsu 214062; ${ }^{2}$ Department of Medical Oncology, \\ Affiliated Hospital of Jiangnan University, Wuxi Cancer Institute, Wuxi, Jiangsu 214062, P.R. China
}

Received October 13, 2014; Accepted June 22, 2015

DOI: $10.3892 / \mathrm{mmr} .2015 .4050$

\begin{abstract}
B7-H3, a newly identified co-stimulatory molecule, has been reported to be highly expressed in a number of types of cancer and is associated with a poor prognosis. Transwell experiments and a wound-healing assay were used to detect the role of over-expressed B7-H3 on cell migration and invasion in colorectal cancer (CRC) cells. The expression level of matrix metallopeptidase 9 (MMP-9) was further investigated by zymography experiments and western blot analysis, and involvement of the Janus kinase 2 (Jak2) signal transducer and activator of transcription 3 (STAT3) signaling pathway was determined using AG490, a Jak2 selective inhibitor. Data showed that overexpression of B7-H3 promoted cell migration and invasion in CRC. Further investigation certified that enhanced expression of B7-H3 elevated MMP-9 through upregulation of the Jak2-Stat3 signaling pathway. Due to its pro-migratory and pro-invasive function, B7-H3 may serve as a therapeutic target in the treatment of CRC.
\end{abstract}

\section{Introduction}

Colorectal cancer (CRC) is the third most common type of cancer and the third leading cause of cancer-related mortality in the United States (1). Incidence rates decreased by $\sim 3 \%$ per year; however, rates increased among adults younger than 50 years-old during the past decade (2001-2010). Therapeutic outcomes of patients with CRC are often far from satisfactory due to recurrence and metastasis, as the tumors are biologically and molecularly heterogeneous. In recent years, molecular targeted therapy has progressed. However, more reliable prognostic and curative biomarkers identifying patients with increased risk of disease recurrence and metastasis are required.

Correspondence to: Dr Bo Jiang or Dr Dong Hua, Department of Medical Oncology, Affiliated Hospital of Jiangnan University, Wuxi Cancer Institute, 200 Huihe Road, Wuxi, Jiangsu 214062, P.R. China E-mail: jiangbo007@gmail.com

E-mail: huadong@csco.org.cn

Key words: colorectal cancer, B7-H3, Jak2-Stat3 signaling pathway
B7-H3, a newly identified co-stimulatory molecule, is a member of the B7 family of proteins (2). B7-H3 is highly expressed in numerous types of cancer, and has been demonstrated to promote tumor progression and cancer cell metastasis, as well as to correlate with the malignancy grade and the outcome of tumor patients, including CRC $(3,4)$, acute leukemia (5), glioma (6), hepatocellular carcinoma (7), lung cancer (8), breast cancer (9), prostate cancer (10), osteosarcoma (11), cutaneous melanoma (12) and pancreatic cancer (13). Studies have been conducted regarding the effects of B7-H3 in CRC. Recently, Ingebrigtsen et al $(3,14)$ demonstrated using tissue microarray analysis that B7-H3 expression was associated with clinicopathological parameters and patient outcome in CRC, and nuclear localization of B7-H3 strongly predicts poor outcome in colon cancer. Bin et al (4) also demonstrated that B7-H3 was aberrantly expressed in CD133(+) CRC cells, and the expression level was closely associated with tumor progression. All the data suggest that B7-H3 may be a useful prognostic and therapeutic marker for CRC. However, the exact role of B7-H3 in CRC remains ambiguous.

Matrix metalloproteases (MMPs) are important in tumor growth, invasion and metastasis (15). Studies have shown that matrix metallopeptidase 9 (MMP-9), one of the most important MMPs, functioned in the migration, invasion and metastasis of numerous types of cancer, including CRC, through various signaling pathways (16-23). MMP-9, activated by astrocyte elevated gene-1 (24), ERK-dependent induced MMP-9 (25) and the p38-MMP-9 pathway (26), increases the invasiveness of CRC. In a recent study, B7-H3 promoted the expression of MMP-9 in a murine inflammatory model (11). However, to date, no studies have been conducted to investigate the correlation between MMP-9 and B7-H3 expression in CRC.

The present study, aimed to investigate the role of B7-H3 in cell migration and invasion in $\mathrm{CRC}$, and the possible signaling pathway involved.

\section{Materials and methods}

Cell lines and culture. Two human CRC cell lines, SW480 and HCT8 (American Type Culture Collection, Manassas, VA, USA), had different expression of B7-H3. SW480 cells were constructed with high expression of B7-H3 (SW480-B7-H3-EGFP), and HCT8 cells stably transfected with B7-H3 siRNA (HCT8-shB7-H3) in our laboratory. At 
the same time, cells transfected with pIRES2-enhanced green fluorescent protein (EGFP) were used as negative controls (SW480-NC and HCT8-NC). Cells were maintained in RPMI-1640 medium (HyClone GE Healthcare Life Sciences, South Logan, UT, USA) supplemented with $10 \%$ fetal bovine serum (FBS; Gibco BRL, Grand Island, NY, USA) at $37^{\circ} \mathrm{C}$ in a humidified atmosphere with $5 \% \mathrm{CO}_{2}$. Cells were harvested using $0.25 \%$ trypsin/EDTA (Invitrogen Life Technologies, Carlsbad, CA, USA).

Antibodies and reagents. Anti-human Janus kinase 2 (Jak2; 2863-1), phosphor-Jak2 (pY1007/1008; p-Jak2) (1477-1), signal transducer and activator of transcription 3 (Stat3; 3566-1) and phospho-Stat3 (pY705; p-Stat3) (2236-1) antibodies were purchased from Epitomics (Burlingame, CA, USA). Antibodies against B7-H3 (sc-376769) and MMP-9 (sc-21733) were purchased from Santa Cruz Biotechnology, Inc (Dallas, TX, USA). The horseradish peroxidase-conjugated secondary anti-mouse and anti-rabbit IgG antibodies and antibodies against GAPDH were obtained from Beyotime Biotechnology Inc. (Nantong, China). A Cytoplasmic Protein Extraction kit and a BCA Protein Assay kit were purchased from Beyotime Biotechnology Inc.

AG490, a Jak2 protein tyrosine kinase inhibitor, was purchased from Sigma-Aldrich (St. Louis, MO, USA; T3434) and a stock solution of AG490 (100 mmol/l) was prepared by re-suspension in dimethly sulfoxide (Sigma-Aldrich).

Protein preparation and western blot analysis. SW480-B7-H3-EGFP/SW480-NC or HCT8-shB7-H3/NC/ HCT8-NC cells $\left(5 \times 10^{5}\right)$ were cultured for $48 \mathrm{~h}$ in a 6 -well plate. Then the conditioned medium (CM) was collected by centrifugation at $15,294 \mathrm{x}$ g for $15 \mathrm{~min}$ at $4^{\circ} \mathrm{C}$, while cells were harvested and cell lysates were prepared using RIPA lysis buffer (Beyotime Biotechnology Inc.) containing phosphatase inhibitor, protease inhibitor and $1 \mathrm{mmol} / 1 \mathrm{PMSF}$ (Beyotime Biotechnology Inc.) for $20 \mathrm{~min}$ on ice and stored at $-80^{\circ} \mathrm{C}$ for later use. The protein content in $\mathrm{CM}$ and the lysates was measured by a BCA Protein Assay kit. For western blot analysis, equal quantities of total proteins were resolved over $10 \%$ tris-glycine polyacrylamide gels (consisting of $4 \mathrm{ml}$ water, $3.3 \mathrm{ml}$ of $30 \%$ Acr-Bis $(29: 1)$, $2.5 \mathrm{ml}$ of $1.5 \mathrm{~mol} / \mathrm{l}$ Tris (pH 8.8), $100 \mu 1$ of $10 \%$ SDS, $100 \mu 110 \%$ ammonium persulfate and $5 \mu \mathrm{l}$ TEMED for a total volume of $10 \mathrm{ml}$ ) under non-reduced conditions, transferred onto polyvinylidene difluoride membranes (Merck Millipore, Billerica, MA, USA), and subsequently incubated in blocking buffer (5\% non-fat dry milk in phosphate-buffered saline) for $1 \mathrm{~h}$ at room temperature. The blots were incubated with the appropriate primary antibody, washed with TBST (Tris-buffered saline buffer with $0.2 \%$ Tween-20), and incubated with a horseradish peroxidase (HRP)-conjugated secondary antibody. The blots were detected with chemiluminescence (Beyo ECL Plus, Beyotime Biotechnology Inc.) followed by autoradiography (Bio-Rad ChemicDoc $^{\mathrm{TM}}$ XRS+imaging system and Image Lab software version 4.0.1; Bio-Rad, Hercules, CA, USA). Relative quantities of protein were quantified by absorbance analysis. The level was normalized to GAPDH, a domestic loading control.

SW480-B7-H3-EGFP and SW480-NC cells $\left(5 \times 10^{5}\right)$ were treated with $100 \mu \mathrm{mol} / \mathrm{l}$ AG490 or left untreated. After $48 \mathrm{~h}$,
$\mathrm{CM}$ was collected by centrifugation at 15,294 $\mathrm{x} \mathrm{g}$ for $15 \mathrm{~min}$ at $4^{\circ} \mathrm{C}$, while cells were harvested and cell lysates were prepared for western blot analysis as described above.

Zymography experiments. To investigate the effects of overexpression of B7-H3 on MMP-9 activation, $5 \times 10^{5} \mathrm{SW} 480-\mathrm{B} 7-\mathrm{H} 3-\mathrm{EGFP} / \mathrm{SW} 480-\mathrm{NC}$ or HCT8-shB7-H3/HCT8-NC cells were plated in a 6-well plate and cultured for $48 \mathrm{~h}$. The $\mathrm{CM}$ was collected by centrifugation at $15,294 \mathrm{x}$ g for $15 \mathrm{~min}$ at $4^{\circ} \mathrm{C}$. The samples containing an equal quantity of total protein were mixed with sample buffer in the absence of reducing agent and loaded onto zymography SDS-polyacrylamide gels containing gelatin $(0.5 \mathrm{mg} / \mathrm{ml})$ as described previously (27). The gels were incubated in incubation buffer $(50 \mathrm{mmol} / \mathrm{l} \mathrm{Tris-HCl}$; pH 7.5) containing $100 \mathrm{mmol} / \mathrm{l}$ $\mathrm{CaCl}_{2}, 1 \mu \mathrm{mol} / 1 \mathrm{ZnCl}_{2}, 1 \%$ (v/v) Triton X-100, and $0.02 \%(\mathrm{w} / \mathrm{v})$ $\mathrm{NaN}_{3}$ for $16 \mathrm{~h}$. The gels were stained with Coomassie Blue and de-stained. Negative staining showed the zones of gelatinolytic activity of MMP-9.

To further determine the effect of AG490 on MMP-9 activation, 5x10 5 SW480-B7-H3-EGFP or SW480-NC cells were plated in a 6-well plate and treated with $100 \mu \mathrm{mol} / \mathrm{l} \mathrm{AG490}$ for $48 \mathrm{~h}$ or left untreated. The CM was collected, and the gelatinolytic activity of MMP-9 was detected by zymography as described above.

Cell migration and invasion assay. The migration and invasion assay was performed using Transwell cell culture chambers (Corning, Corning, NY, USA) as described previously (28).

For the migration assay, the confluent monolayers of SW480-B7-H3-EGFP and SW480-NC cells were harvested with trypsin-EDTA and centrifuged at $800 \mathrm{x}$ g for $10 \mathrm{~min}$. Cell resuspension (200 $\mu 1,2 \times 10^{5}$ cells/ml) in RPMI-1640 was added to the upper chamber of the prehydrated polycarbonate membrane filter. The lower chamber was filled with RPMI-1640 medium with $10 \%$ FBS, which acted as a chemoattractant. Then cells were incubated in a humidified incubator in 5\% $\mathrm{CO}_{2}$ at $37^{\circ} \mathrm{C}$ for $24 \mathrm{~h}$. The non-migrated cells on the upper side of the filter were scraped, and the filter was washed with PBS and deionised water, and then air-dried. The migrated cells on the reverse side of the filter were fixed with methanol and stained with Giemsa. Images were captured using an inverted microscope (Olympus IX71, Tokyo, Japan).

For the invasion assay, the prehydrated polycarbonate membrane filter of the Transwell cell culture chambers was pre-coated with BD Matrigel ${ }^{\mathrm{TM}}$ Basement Membrane Matrix (356234, BD BioSciences, Franklin Lakes, NJ, USA). A $200 \mu 1$ cell re-suspension of SW480-B7-H3-EGFP and SW480-NC ( $2 \times 10^{5}$ cells $/ \mathrm{ml}$ ) in RPMI-1640 was added to the upper chamber of the Boyden chamber. RPMI-1640 medium with 10\% FBS was used in the lower chamber, which acted as a chemoattractant. After $48 \mathrm{~h}$, the non-invaded cells and Matrigel from the upper side of the filter were scraped and removed using a moist cotton swab. The invaded cells on the lower side of the filter were fixed with methanol and stained with Giemsa. Images were captured using an inverted microscope (Olympus IX71).

Wound healing assay. One day prior to the wound healing assay, SW480-B7-H3-EGFP or SW480-NC cells were plated in a 6-well plate so that cells were $90-95 \%$ confluent at the 
time of the assay. Wounds with a constant diameter were made. Cells were maintained in RPMI-1640 with $0.5 \%$ FBS. Images of the wound area were captured using an inverted microscope (Olympus IX71) everyday for 5-6 days.

Statistical analysis. Statistical differences were determined by Student's t-test using GraphPad Prism 5 software (GraphPad Software Inc., La Jolla, CA, USA). P $<0.05$ was considered to indicate a statistically significant difference. All experiments were conducted at least three times.

\section{Results}

Overexpression of $\mathrm{B} 7-\mathrm{H} 3$ promotes cell migration and invasion. To delineate the role of $\mathrm{B} 7-\mathrm{H} 3$ on cell migration and invasion in CRC cells, a wound healing assay, and a cell migration and invasion assay were performed (Fig. 1). Transwell experiments (without Matrigel on the filter) and wound assay results indicated that enhanced expression of B7-H3 promoted cell migration, 7.4 \pm 1.5 fold SW480-B7-H3-EGFP vs. SW480-NC (Fig. 1A upper panel, Fig. 1B). In addition, enhanced expression of B7-H3 also promoted cell invasion (with Matrigel on the filter), 5.07 \pm 0.2 fold SW480-B7-H3-EGFP vs. SW480-NC (Fig. 1A lower panel).

Overexpression of B7-H3 upregulates MMP-9. To determine the mechanism underlying the effect of enhanced expression of B7-H3 on the promotion of cell migration and invasion, the present study aimed to delineate the role of MMP family member, MMP-9. Zymography experimental data revealed that over-expression of B7-H3 in SW480-B7-H3-EGFP cells (Fig. 2A lower panel) significantly elevated the proteolytic activity of MMP-9 when compared with control cells, SW480-NC (Fig. 2A upper panel). Moreover, western blot analysis demonstrated that enhanced expression of B7-H3 also promoted the expression of MMP-9 protein (Fig. 2A upper panel). B7-H3 was downregulated in HCT8-shB7-H3 cells. The proteolytic effect of MMP-9 in CM of HCT8-shB7-H3 cells was significantly reduced compared with that in the CM of control cells, HCT8-NC. The expression level of MMP-9 protein in the CM of HCT8-shB7-H3 cells was also reduced (Fig. 2B). These results demonstrate that enhanced expression of B7-H3 promoted cell migration and invasion, at least partially through upregulation of MMP-9.

Overexpression of B7-H3 enhances cell migration and invasion in CRC cells via activation of the Jak2-Stat3 pathway. The phenomenon that B7-H3 enhanced cell migration and invasion through upregulation of MMP-9 was observed, and the present study aimed to identify the signaling pathway involved. The Jak2/Stat3 pathway has been reported to be key in cell migration, invasion and metastasis, and inhibition of Jak2/Stat3 signaling induced CRC cell apoptosis, cell arrest and reduced tumor cell invasion (29-31). Thus, it was analyzed whether this pathway could be activated by B7-H3 in CRC. SW480-B7-H3-EGFP cells were treated with AG490, a Jak2-selective inhibitor, at a final concentration of $100 \mu \mathrm{mol} / \mathrm{l}$ for $48 \mathrm{~h}$. CM was collected and used for detection of MMP-9 by western blot analysis and zymography, and

\section{A SW480-NC}
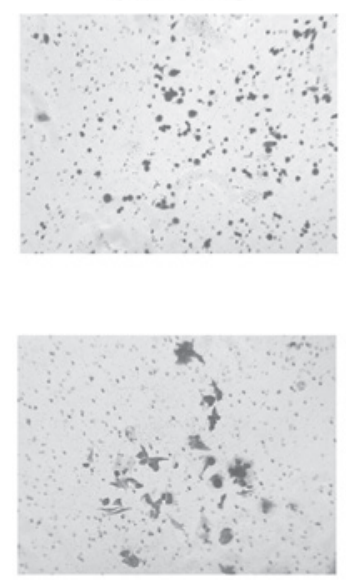

B
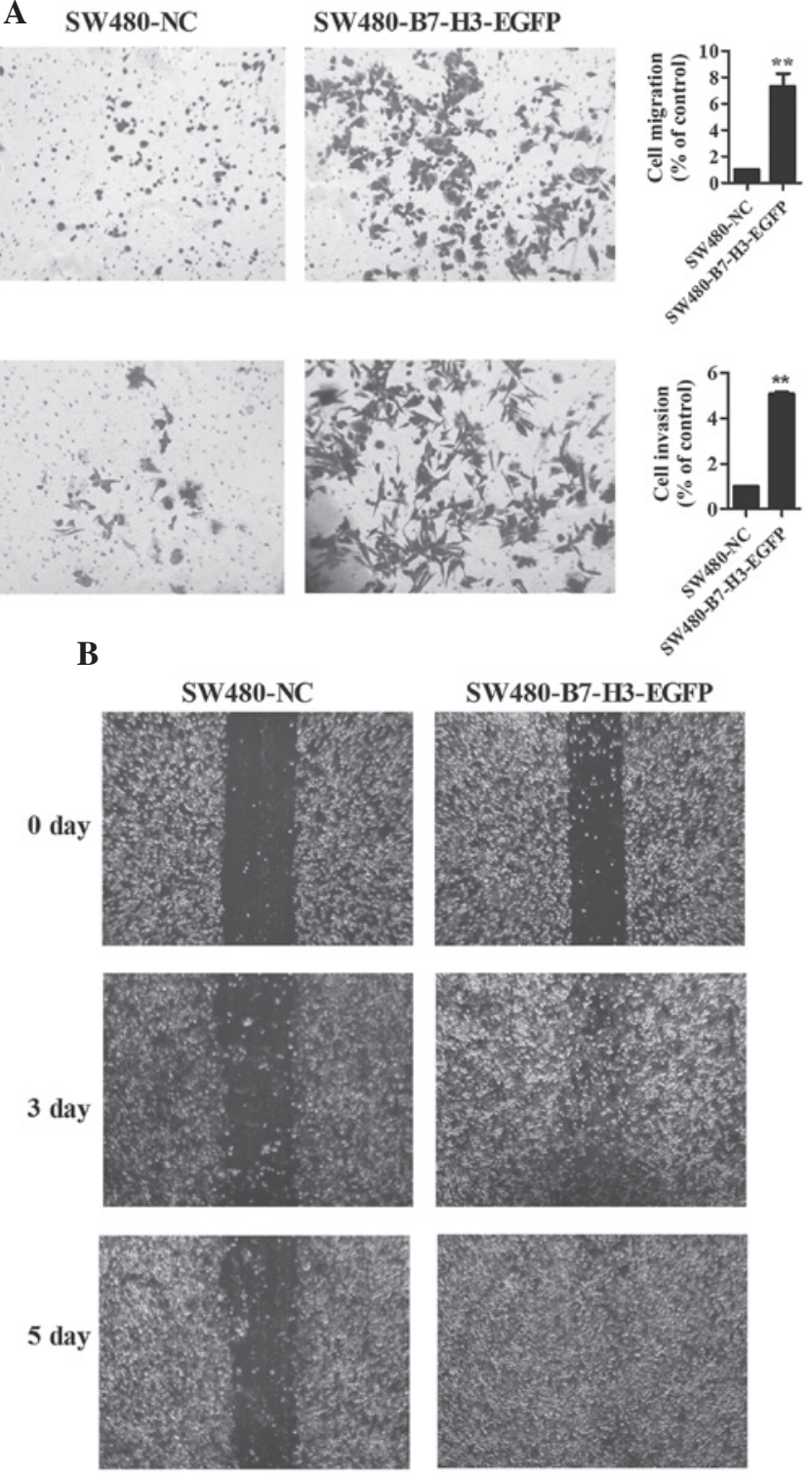

Figure 1. Overexpression of $\mathrm{B} 7-\mathrm{H} 3$ promotes cell migration and invasion (A) SW480-B7-H3-EGFP or SW480-NC $\left(4 \times 10^{4}\right)$ cells were used for Transwell assays. The prehydrated polycarbonate membrane filter of Transwell cell

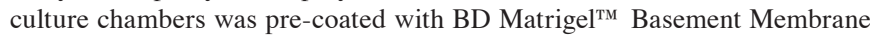
Matirx (lower panel) for the cell invasion assay or were not pre-coated for cell migration assay (upper panel). Migrated cells were stained, photographed and migration of SW480-B7-H3-EGFP cells were quantified and represented in form of bar graph. Statistical analysis was performed. ${ }^{* *} \mathrm{P}<0.01$. Magnification, x200 (B) Images of the wound healing assay were captured on days 0, 3 and 5 . Magnification, $x 40$. Data are representative of three independent experiments. EGFP, enhanced green fluorescent protein; NC, normal control.

whole-cell lysates were used for detection of Jak2, Stat3 and their phosphorylated forms by western blot analysis (Fig. 3A). Data showed that the phosphorylation levels of Jak2 and Stat3 increased following upregulation of B7-H3 expression; however, both were significantly reduced after AG490 treatment due to the inhibition of tyrosine phosphorylation of Jak2 (Fig. 3A upper panel). In addition, the proteolytic activity and protein expression of MMP-9 increased following upregulated expression of $\mathrm{B} 7-\mathrm{H} 3$, but significantly reduced after AG490 treatment, as determined by zymography and western blot analysis, paralleled with the regulation of the phosphorylation level of Jak2 and Stat3 (Fig. 3A lower panel). These 

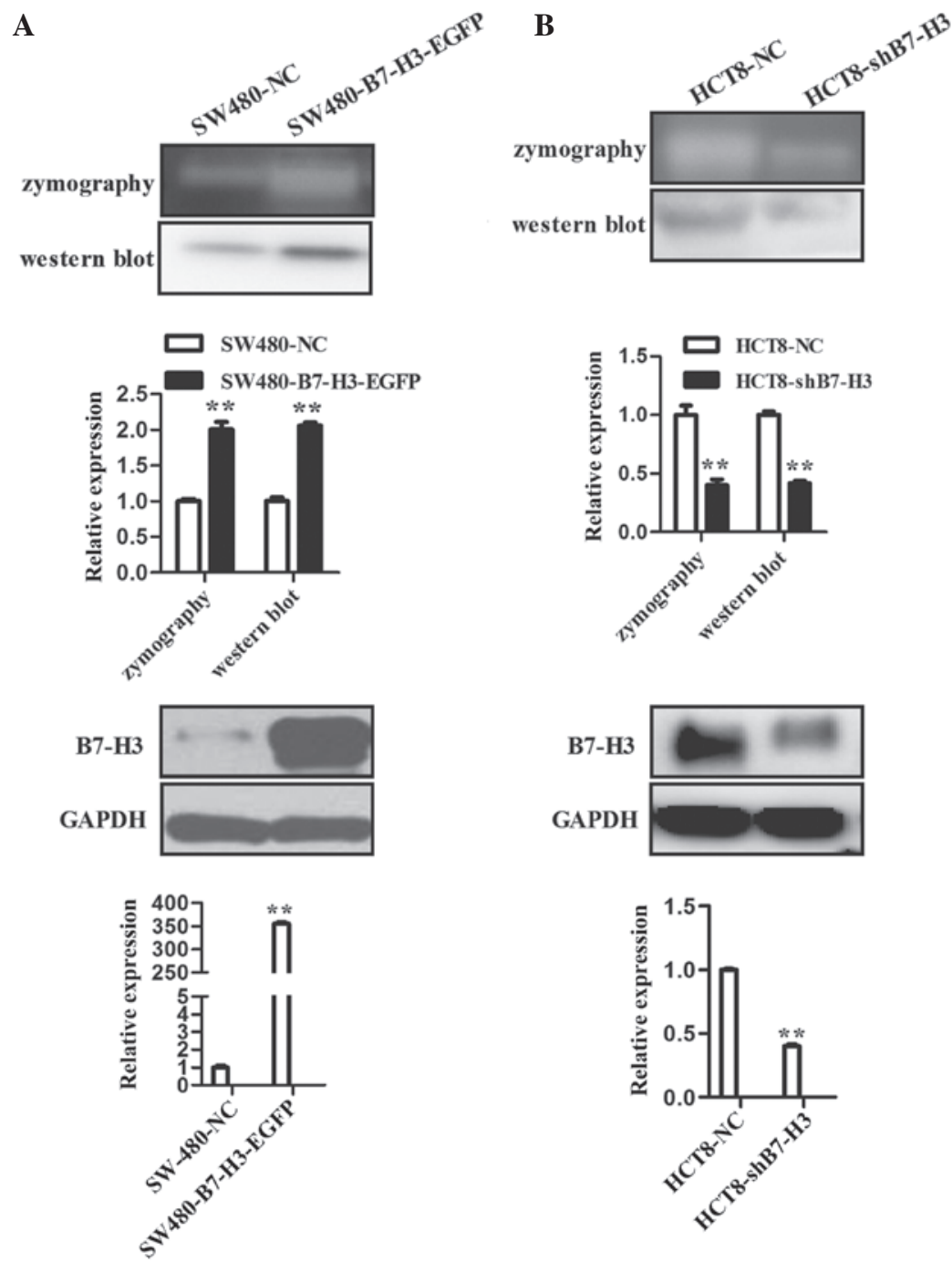

Figure 2. Overexpression of B7-H3 upregulated MMP-9. (A) SW480-B7-H3-EGFP and SW480-NC cells (5x105) and (B) HCT8-shB7-H3 or HCT8-NC cells were cultured for $48 \mathrm{~h}$, MMP-9 activation and expression in CM was detected by zymography and western blot analysis (upper panel) and B7-H3 in cell lysates was detected by western blot analysis (lower panel). GAPDH served as a domestic loading control in cell lysates. The quantification results were also shown and statistical analysis was performed. ${ }^{* *} \mathrm{P}<0.01$. Data are representative of three independent experiments. MMP-9, matrix metallopeptidase 9; EGFP, enhanced green fluorescent protein; NC, normal control; CM, conditioned medium.

results indicate that MMP-9 is a downstream target of B7-H3 and the upregulation of MMP-9 induced by B7-H3 can be blocked by AG490 (a Jak2/Stat 3 signaling pathway specific inhibitor). Thus, it was hypothesized that overexpression of B7-H3 increased the phosphorylation of Jak2, which led to increased phosphorylation of Stat3, resulting in increased expression of MMP-9 (Fig. 3B). Thus, it was confirmed that the Jak2/Stat3/MMP-9 signaling pathway was important in regulating the cell migration and invasion induced by $\mathrm{B} 7-\mathrm{H} 3$ in CRC.

\section{Discussion}

B7 family members are regarded as co-stimulatory/co-inhibitory immune molecules that integrate $\mathrm{T}$ cell receptor signaling to regulate $\mathrm{T}$ cell function. In this study, it was demonstrated that $\mathrm{B} 7-\mathrm{H} 3$ exhibits a non-immune role in CRC, promoting MMP-9 expression in CRC cells. The elevated MMP-9 expression level in CRC cell supernatants can partly explain the phenomena that the expression level of $\mathrm{B} 7-\mathrm{H} 3$ in CRC tissue is positively correlated with $\mathrm{T}$ stage of patients $(3,4)$ and negatively correlated with overall survival of CRC (14). Furthermore, it has previously been shown that B7-H3 regulates the expression of Bcl-2, Bcl-xl and Bax via the Jak2/Stat3 signaling pathway in order to increase the anti-apoptotic ability of cancer cells (32). In the present study it was demonstrated that $\mathrm{B} 7-\mathrm{H} 3$ promotes cell migration and invasion through the Jak2/Stat3/MMP9 signaling pathway.

Ingebrigtsen et al $(3,14)$ and Bin et al $(4)$ showed that high B7-H3 expression predicted poor outcome in patients with colon cancer, and the high expression level in CD133(+) $\mathrm{CRC}$ cells was associated with tumor progression as determined by tissue microarray analysis. However, the molecular regulatory mechanisms have not yet been investigated. To the best of our knowledge, the present study demonstrated that B7-H3 promoted cancer cell migration and invasion via Jak2/Stat3/MMP-9 signaling pathway for the first time.

MMPs degrade all types of extracellular matrix proteins, and are regarded as a marker of malignant tumor invasion and metastasis (33-35). MMP-2 and MMP-9 are the most 
A

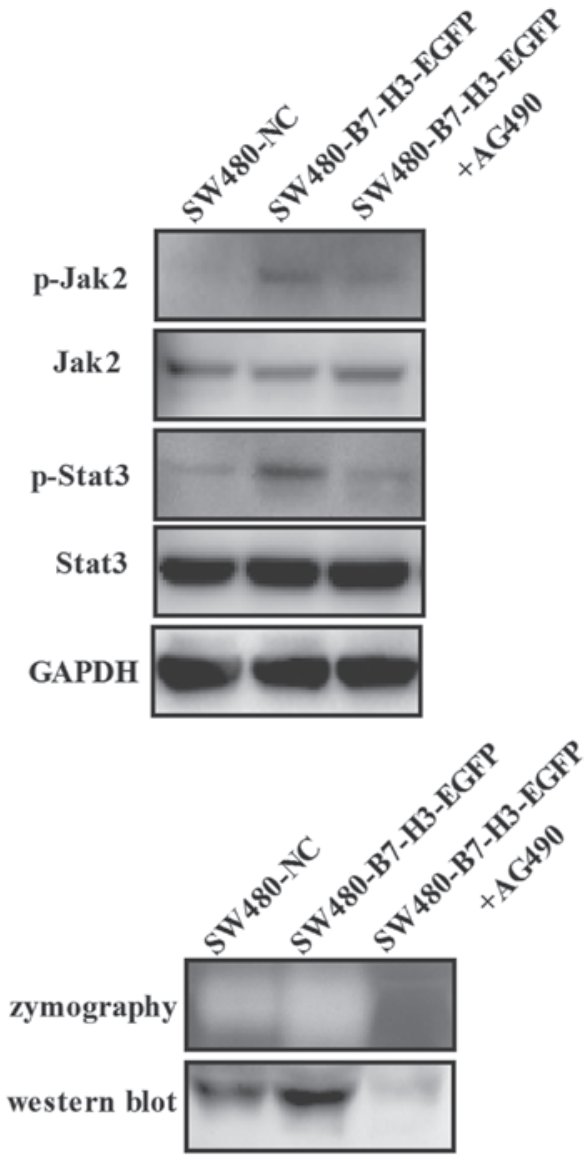

B

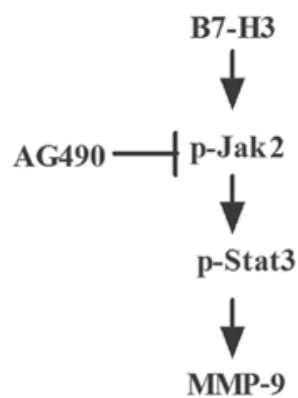

Figure 3. Overexpression of B7-H3 enhances cell migration and invasion in CRC cells via activation of the Jak2/Stat3/MMP-9 pathway. (A) SW480-B7-H3-EGFP or SW480-NC cells $\left(5 \times 10^{5}\right)$ were treated or with AG490 for 48 h or left untreated. Jak2, p-Jak2, Stat3 and p-Stat3 in cell lysates were detected by western blot analysis (upper panel) and MMP-9 activation and expression in CM was detected by zymography and western blot analysis (lower panel). Equal loading of lysates was confirmed by stripping immunoblots and re-probing for GAPDH. Results shown are representative of three independent experiments. (B) A simple pathway map for B7-H3 regulating cell migration and invasion in CRC cells. Jak2, Janus kinase 2; Stat3, signal transducer and activator of transcription 3; MMP-9, matrix metallopeptidase 9; EGFP, enhanced green fluorescent protein; NC, normal control; p-, phosphorylated; CM, conditioned medium.

important molecules in the MMP family. B7-H3 and MMP-2 were shown to correlate with infiltration depth in pancreatic cancer (4), and knock-down of B7-H3 led to reduced expression of MMP-2 (36). In addition, B7-H3 was shown to increase the expression of MMP-9 in murine models of inflammation (11). The correlation between B7-H3 and MMP-9 requires further investigation in malignant tumors. In the present study, it was shown that overexpression of B7-H3 elevated the MMP-9 expression level in CRC. However, whether B7-H3 can affect the levels of other MMPs, such as MMP-2, remains to be investigated.

Abnormalities in the Jak2/Stat3 pathway are involved in the pathogenesis of CRC. Inhibition of Jak2/Stat3 signaling induces CRC cell apoptosis, cell arrest and reduces tumor cell invasion (29-31). MMPs, including MMP-2, -9 and -10, have been reported to be downstream of this pathway (37-39). Another study showed that blocking B7-H3 resulted in inhibition of activated Jak2/Stat 3 in breast cancer cells (40). It was also previously demonstrated that $\mathrm{B} 7-\mathrm{H} 3$ possesses an anti-apoptotic function through the Jak2-Stat3 signaling pathway (32). In the present study, B7-H3 activated the Jak2/Stat3 signaling pathway, and the high phosphorylation level of Jak2 and Stat3, led to the upregulation of MMP-9. Furthermore, AG490, a specific inhibitor of Jak2, was used to inhibit Jak2/Stat 3 signaling. It was demonstrated that AG490 could significantly reduce the phosphorylation level of Jak2 and Stat3, and downregulate the expression of MMP-9. These results indicate that MMP-9 is a downstream target of the B7-H3/Jak2/Stat3 signaling pathway, and B7-H3 promotes CRC invasion through the Jak2/Stat3/MMP-9 pathway. Due to the complex signaling pathways present in cancer cells, successful targeted therapies are becoming more difficult to identify. Each cellular process is controlled by various signaling networks. Thus, B7-H3 may also promote CRC cell migration and invasion through other signal networks, which required to be determined.

Based on above results, we plan to analyze other MMP family members and tissue inhibitor of metalloproteinase family members in cells with B7-H3 overexpression and knock down in the subsequence studies, and to identify possible proteins that mediate $\mathrm{B} 7-\mathrm{H} 3$ signaling resulting in Jak2 phosphorylation.

In conclusion, it was demonstrated that high B7-H3 expression could promote cancer cell migration and invasion in CRC. This is the first report to show the molecular mechanisms underlying this effect. Overexpressed B7-H3 elevated MMP-9 resulting in pro-migratory and pro-invasive abilities through the Jak2-Stat3 pathway. These findings indicate a novel role for $\mathrm{B} 7-\mathrm{H} 3$ in the regulation of the invasive capacity of CRC cells and it may be a potential therapeutic target to prevent metastasis.

\section{Acknowledgements}

This study has been supported in part by the grants from the Jiangsu Provincial Health Bureau of Medical (grant no. RC2011030), the Wuxi Hospital Management Center (grant no. YCZ1108) and the Natural Science Foundation of Jiangsu Province (grant no. BK2012542).

\section{References}

1. Siegel R, Desantis C and Jemal A: Colorectal cancer statistics, 2014. CA Cancer J Clin 64: 104-117, 2014.

2. Sun M, Richards S, Prasad DV, Mai XM, Rudensky A and Dong C: Characterization of mouse and human B7-H3 genes. J Immunol 168: 6294-6297, 2002. 
3. Ingebrigtsen VA, Boye K, Nesland JM, Nesbakken A Flatmark K and Fodstad $\varnothing:$ B7-H3 expression in colorectal cancer: Associations with clinicopathological parameters and patient outcome. BMC Cancer 14: 602, 2014.

4. Bin Z, Guangbo Z, Yan G, Huan Z, Desheng L and Xueguang Z: Overexpression of $\mathrm{B} 7-\mathrm{H} 3$ in $\mathrm{CD} 133^{+}$colorectal cancer cells is associated with cancer progression and survival in human patients. J Surg Res 188: 396-403, 2014.

5. Hu Y, Lv X, Wu Y, Xu J, Wang L, Chen W, Zhang W, Li J, Zhang S and Qiu H: Expression of costimulatory molecule B7-H3 and its prognostic implications in human acute leukemia. Hematology 20: 187-195, 2015.

6. Baral A, Ye HX, Jiang PC, Yao Y and Mao Y: B7-H3 and B7-H1 expression in cerebral spinal fluid and tumor tissue correlates with the malignancy grade of glioma patients. Oncol Lett 8: 1195-1201, 2014

7. Wang F, Wang G, Liu T, Yu G, Zhang G and Luan X: B7-H3 was highly expressed in human primary hepatocellular carcinoma and promoted tumor progression. Cancer Invest 32: 262-271, 2014.

8. Sun J, Mao Y, Zhang YQ, Guo YD, Mu CY, Fu FQ and Zhang XG: Clinical significance of the induction of macrophage differentiation by the costimulatory molecule B7-H3 in human non-small cell lung cancer. Oncol Lett 6: 1253-1260, 2013.

9. Maeda N, Yoshimura K, Yamamoto S, Kuramasu A, Inoue M, Suzuki N, Watanabe Y, Maeda Y, Kamei R, Tsunedomi R, et al: Expression of B7-H3, a potential factor of tumor immune evasion in combination with the number of regulatory $\mathrm{T}$ cells, affects against recurrence-free survival in breast cancer patients. Ann Surg Oncol 21 (Suppl 4): S546-S554, 2014.

10. Roth TJ, Sheinin Y, Lohse CM, Kuntz SM, Frigola X, Inman BA, Krambeck AE, McKenney ME, Karnes RJ, Blute ML, et al: B7-H3 ligand expression by prostate cancer: A novel marker of prognosis and potential target for therapy. Cancer Res 67: 7893-7900, 2007.

11. Chen X, Bai Y, Cui W, Wang Z, Zhang G, Xu Y, Zhu X, Li Y and Wang JH: Effects of B7-H3 on the inflammatory response and expression of MMP-9 in mice with pneumococcal meningitis. J Mol Neurosci 50: 146-153, 2013.

12. Wang J, Chong KK, Nakamura Y, Nguyen L, Huang SK, Kuo C, Zhang W, Yu H, Morton DL and Hoon DS: Hoon. B7-H3 associated with tumor progression and epigenetic regulatory activity in cutaneous melanoma. J Invest Dermatol 133: 2050-2058, 2013.

13. Zhao X, Li DC, Zhu XG, Gan WJ, Li Z, Xiong F, Zhang ZX, Zhang GB, Zhang XG and Zhao H: B7-H3 overexpression in pancreatic cancer promotes tumor progression. Int J Mol Med 31: 283-291, 2013

14. Ingebrigtsen VA, Boye K, Tekle C, Nesland JM, Flatmark K and Fodstad O: B7-H3 expression in colorectal cancer: Nuclear localization strongly predicts poor outcome in colon cancer. Int J Cancer 131: 2528-2536, 2012.

15. Artacho-Cordón F, Ríos-Arrabal S, Lara PC, Artacho-Cordón A, Calvente I and Nńñez MI: Matrix metalloproteinases: Potential therapy to prevent the development of second malignancies after breast radiotherapy. Surg Oncol 21: e143-e151, 2012.

16. Hu S, Li L, Yeh S, Cui Y, Li X, Chang HC, Jin J and Chang C: Infiltrating $\mathrm{T}$ cells promote prostate cancer metastasis via modulation of FGF11 >miRNA-541> androgen receptor (AR) > MMP9 signaling. Mol Oncol 9: 44-57, 2015.

17. Jian H, Zhao Y, Liu B and Lu S: SEMA4b inhibits MMP9 to prevent metastasis of non-small cell lung cancer. Tumour Biol 35: 11051-11056, 2014

18. Jang SY, Kim A, Kim JK, Kim C, Cho YH, Kim JH, Kim CH and Lee JY: Metformin inhibits tumor cell migration via down-regulation of MMP9 in tamoxifen-resistant breast cancer cells. Anticancer Res 34: 4127-4134, 2014.

19. Zhou DN, Deng YF, Li RH, Yin P and Ye CS: Concurrent alterations of RAGE, RECK and MMP9 protein expression are relevant to Epstein-Barr virus infection, metastasis and survival in nasopharyngeal carcinoma. Int J Clin Exp Pathol 7: 3245-3254, 2014.

20. Huang Q, Lan F, Wang X, Yu Y, Ouyang X, Zheng F, Han J, Lin Y, Xie Y, Xie F, et al: IL-1 $\beta$-induced activation of p38 promotes metastasis in gastric adenocarcinoma via upregulation of AP-1/c-fos, MMP2 and MMP9. Mol Cancer 13: 18, 2014.

21. Li L, Tan J, Zhang Y, Han N, Di X, Xiao T, Cheng S, Gao Y and Liu Y: DLK1 promotes lung cancer cell invasion through upregulation of MMP9 expression depending on Notch signaling. PLoS One 9: e91509, 2014.
22. Han S, Han L, Yao Y, Sun H, Zan X and Liu Q: Activated hepatic stellate cells promote hepatocellular carcinoma cell migration and invasion via the activation of FAK-MMP9 signaling. Oncol Rep 31: 641-648, 2014

23. Feng X, Miao G, Han Y and Xu Y: CARMA3 is overexpressed in human glioma and promotes cell invasion through MMP9 regulation in A172 cell line. Tumour Biol 35: 149-154, 2014.

24. Song H, Tian Z, Qin Y, Yao G, Fu S and Geng J: Astrocyte elevated gene-1 activates MMP9 to increase invasiveness of colorectal cancer. Tumour Biol 35: 6679-6685, 2014.

25. Kim HC, Kim YS, Oh HW, Kim K, Oh SS, Kim JT, Kim BY, Lee SJ, Choe YK, Kim DH, et al: Collagen triple helix repeat containing 1 (CTHRC1) acts via ERK-dependent induction of MMP9 to promote invasion of colorectal cancer cells. Oncotarget 5: 519-529, 2014.

26. Wei SC, Tsao PN, Weng MT, Cao Z and Wong JM: Flt-1 in colorectal cancer cells is required for the tumor invasive effect of placental growth factor through a 338 -MMP9 pathway. J Biomed Sci 20: 39, 2013

27. Kale S, Raja R, Thorat D, Soundararajan G, Patil TV and Kundu GC: Osteopontin signaling upregulates cyclooxygenase-2 expression in tumor-associated macrophages leading to enhanced angiogenesis and melanoma growth via $\alpha 9 \beta 1$ integrin. Oncogene 33: 2295-2306, 2014

28. Rangaswami H, Bulbule A and Kundu GC: Nuclear factor-inducing kinase plays a crucial role in osteopontin-induced MAPK/IkappaBalpha kinase-dependent nuclear factor kappaB-mediated promatrix metalloproteinase-9 activation. J Biol Chem 279: 38921-38935, 2004.

29. Du W, Hong J, Wang YC, Zhang YJ, Wang P, Su WY, Lin YW, Lu R, Zou WP, Xiong H and Fang JY: Inhibition of JAK2/STAT3 signalling induces colorectal cancer cell apoptosis via mitochondrial pathway. J Cell Mol Med 16: 1878-1888, 2012.

30. Xiong H, Chen ZF, Liang QC, Du W, Chen HM, Su WY, Chen GQ, Han ZG and Fang JY: Inhibition of DNA methyltransferase induces G2 cell cycle arrest and apoptosis in human colorectal cancer cells via inhibition of JAK2/STAT3/STAT5 signalling. J Cell Mol Med 13: 3668-3679, 2009.

31. Xiong H, Zhang ZG, Tian XQ, Sun DF, Liang QC, Zhang YJ, Lu R, Chen YX and Fang JY: Inhibition of JAK1, 2/STAT3 signaling induces apoptosis, cell cycle arrest and reduces tumor cell invasion in colorectal cancer cells. Neoplasia 10: 287-297, 2008.

32. Zhang T, Jiang B, Zou ST, Liu F and Hua D: Overexpression of B7-H3 augments anti-apoptosis of colorectal cancer cells by Jak2-STAT3. World J Gastroenterol 21: 1804-1813, 2015.

33. Kessenbrock K, Plaks V and Werb Z: Matrix metalloproteinases: Regulators of the tumor microenvironment. Cell 141: 52-67, 2010.

34. Curran S and Murray GI: Matrix metalloproteinases: Molecular aspects of their roles in tumour invasion and metastasis. Eur $\mathrm{J}$ Cancer 36: 1621-1630, 2000.

35. Egeblad M and Werb Z: New functions for the matrix metalloproteinases in cancer progression. Nat Rev Cancer 2: 161-174, 2002.

36. Tekle C, Nygren MK, Chen YW, Dybsjord I, Nesland JM, Maelandsmo GM and Fodstad O: B7-H3 contributes to the metastatic capacity of melanoma cells by modulation of known metastasis-associated genes. Int J Cancer 130: 2282-2290, 2012.

37. Zhang X, Yin P, Di D, Luo G, Zheng L, Wei J, Zhang J, Shi Y, Zhang $\mathrm{J}$ and $\mathrm{Xu} \mathrm{N}$ : IL-6 regulates MMP-10 expression via JAK2/STAT3 signaling pathway in a human lung adenocarcinoma cell line. Anticancer Res 29: 4497-4501, 2009.

38. Senft C, Priester M, Polacin M, Schröder K, Seifert V, Kögel D and Weissenberger J: Inhibition of the JAK-2/STAT3 signaling pathway impedes the migratory and invasive potential of human glioblastoma cells. J Neurooncol 101: 393-403, 2011.

39. Reis ST, Pontes-Junior J, Antunes AA, Dall'Oglio MF, Dip N, Passerotti CC, Rossini GA, Morais DR, Nesrallah AJ, Piantino C, et al: miR-21 may acts as an oncomir by targeting RECK, a matrix metalloproteinase regulator, in prostate cancer. BMC Urol 12: 14, 2012.

40. Liu H, Tekle C, Chen YW, Kristian A, Zhao Y, Zhou M, Liu Z, Ding Y, Wang B, Mælandsmo GM, et al: B7-H3 silencing increases paclitaxel sensitivity by abrogating Jak $2 /$ Stat 3 phosphorylation. Mol Cancer Ther 10: 960-971, 2011. 